\title{
Application of the F-statistic of the Fisher-Snedecor distribution to analyze the significance of the effect of changes in the compression ratio of a diesel engine on the value of the specific enthalpy of the exhaust gas flow
}

ARTICLE INFO

Received: 13 July 2021

Revised: 15 August 2021

Accepted: 17 August 2021

Available online: 18 August 2021

The paper discusses the impact of changes in the compression ratio on the operating parameters of a diesel engine, e.g. on the temperature of exhaust gases. It presents the construction of the laboratory test stand, on which experimental measurements were realized. It is characterized how the actual changes of the compression ratio were introduced to the existing engine. The program of experimental investigations taking into account the available test stand and measurement possibilities was described. A statistical and qualitative analysis of the obtained measurement results was made. The use of $F$ statistics of the Fisher-Snedecor distribution was proposed to assess the significance of the effect of compression ratio changes on the specific enthalpy of the exhaust gas stream. The specific enthalpy of exhaust gases was analysed for one cycle of diesel engine work, determined on the basis of the course of quickly varying temperature of exhaust gases. The results of these analyses are discussed and the utilitarian purpose of this type of evaluation in parametric diagnostics of piston engines is presented.

Key words: diesel engine, exhaust gas temperature, Fisher-Snedecor decomposition F statistic, diagnosis

This is an open access article under the CC BY license (http://creativecommons.org/licenses/BY/4.0/)

\section{Introduction}

The compression ratio $\varepsilon$ of the cylinder systems of a piston engine is a value, which has a significant influence on the fuel combustion process in these cylinders and on most of the basic and control parameters of its work, as well as on the emission of harmful and toxic gaseous components in the exhaust gases. Decrease or increase of the $\varepsilon$ value may indicate a state of partial operability or even inoperability of the engine caused, for example, by a loss of tightness or contamination of the cylinder working space. More and more technologically advanced high-power engines ${ }^{1}$, e.g. marine ones, are characterized by limited controllability, manifested, for example, by the possibility of cylinder indicating [14]. Hence the need for parametric diagnosis, based on quickly changing temperature of exhaust gases, recorded in the place of standard measurement, which is required when we talk about marine engines. In this case, the object of examination are constructional elements limiting working spaces of a marine engine, which, due to requirements of classification societies, has a place of standard measurement of exhaust gas temperature. Processes occurring in the inside cylinder spaces are analysed, which in high-power marine engines are analogous to those in the analysed single-cylinder engine. The parameter, which is quickly changing temperature of exhaust gases, can be a valuable source of diagnostic information, provided that the diagnosis methodology based on this parameter is properly prepared. In order to achieve this goal it is important to choose the right measurement technology, tools for mathematical processing as well as statistical and content-related analysis of the obtained results. Conclusions based on the F statistic of the Fisher-Snedecor ${ }^{2}$ distribution allow us to assess the significance of the influence of one input factor on one output factor. The input factor in the discussed case is the structure parameter, i.e. the compression ratio, and the output factor - the specific enthalpy of the exhaust gas stream averaged over one engine operation cycle determined on the basis of quickly varying temperature of the exhaust gas of a diesel engine.

\section{The effect of compression ratio changes on the operating parameters of a diesel engine}

One of the most important values characterizing the piston engine is the compression ratio (determined on the basis of the engine construction data) or the pressure ratio (determined by measuring the pressure of the working medium at the beginning and the end of the compression stroke). This value directly influences the basic engine parameters (torque, power, specific fuel consumption and efficiency) and indirectly affects the control parameter, i.e. exhaust temperature. Thus, the measurement of quickly changing exhaust gas temperature can be a source of diagnostic information about decreased or increased compression ratio resulting from the occurrence of partial serviceability or unserviceability condition.

\subsection{Basic parameters}

The design value on which the thermodynamic parameters of the working medium at the end of the compression stroke depend to a very large degree is the compression ratio, which tells us how many times the volume of the working gas decreased in the cylinder during the piston movement from the bottom dead centre to the top dead centre [12]:

\footnotetext{
${ }^{2}$ It is also called "F-statistic" for shorter in the rest of the paper.
} 


$$
\varepsilon=\frac{\mathrm{v}_{\mathrm{k}}+\mathrm{V}_{\mathrm{s}}}{\mathrm{V}_{\mathrm{k}}}
$$

where: $\mathrm{V}_{\mathrm{s}}$ - volume of cylinder stroke, $\mathrm{V}_{\mathrm{k}}$ - volume of combustion chamber, $\varepsilon$ - compression ratio.

On the other hand, the value determined on the basis of the indicator diagram determined individually for each cylinder [5] is the pressure ratio, defined by the relation:

$$
\varepsilon^{\prime}=\left(\frac{\mathrm{p}_{2}}{\mathrm{p}_{1}}\right)^{\frac{1}{\kappa}}
$$

where: $p_{1}$ - pressure at the beginning of the compression stroke, $\mathrm{p}_{2}$ - pressure at the end of the compression stroke, $\kappa$ - isentropy exponent, $\varepsilon$ ' - compression (pressure) ratio.

The most important basic and control parameters of engine operation, which depend on the compression ratio, include those listed below.

- The compression ratio should be selected so as to ensure self-ignition of the fuel injected into the combustion chamber. It is recommended that the temperature of compression end be about $200^{\circ} \mathrm{C}$ higher than the selfignition temperature of fuel [11]. This allows for so called "soft" engine work and easier cold start in various climatic conditions.

- The overall engine efficiency $\eta_{\mathrm{o}}$, which is the product of the theoretical, indicated and mechanical efficiencies, has a direct effect on the engine operating costs. The theoretical efficiency of the Seiliger-Sabathe circuit, which is implemented in a diesel engine, increases with increasing the value of $\varepsilon$, which can be expressed by the relation [13]:

$$
\eta_{\mathrm{tS}}=1-\frac{1}{\varepsilon^{\kappa-1}} \cdot \frac{\alpha \varphi^{\kappa}-1}{\alpha-1+\alpha \kappa(\varphi-1)}
$$

where: $\eta_{\mathrm{tS}}$ - theoretical efficiency of the SeiligerSabathe cycle, $\varepsilon-$ compression ratio, $\kappa-$ isentropy exponent, $\alpha$ - isochoric pressure rise ratio, $\varphi-$ degree of loading.

In the case of the indicated efficiency $\eta_{i}$, its value decreases as $\varepsilon$ increases. This is because increasing the value of $\varepsilon$ results in an increase in the pressure and temperature of the burning fuel-air mixture. Assuming a constant coolant temperature value, an increase in combustion temperature results in higher cooling losses. A similar trend can be observed for the mechanical efficiency $\eta_{m}\left(\eta_{m}\right.$ decreases with increasing $\left.\varepsilon\right)$. This is due to the increase in pressure during combustion, which results in increased stresses and therefore pressures on the engine components carrying the forces created by these pressures. The dynamic loads on the piston-ringcylinder system increase the friction losses, which are the main component of the losses included in $\eta_{\mathrm{m}}$.

In the case of diesel engines, the nature of the efficiency curve is similar to that of the spark-ignition engines, but the values of $\varepsilon$ are much higher, due to the differences in the nature of the ignition process: for the diesel engine from 14 to 23 , for the spark-ignition engine from 9 to even 19 .

- As the compression ratio increases, specific fuel consumption decreases and engine power and torque increase. However, one should also keep in mind the cur- rent limits of emission of harmful components of exhaust gases $\left(\mathrm{CO}, \mathrm{HC}, \mathrm{NO}_{\mathrm{x}}, \mathrm{CO}_{2}, \mathrm{PM}\right.$, smoke, etc.), the amount of which is in direct relation with these parameters [15]. The concentration of toxic components in the exhaust gas depends primarily on the over-air ratio $\lambda$, and therefore also on the engine load [11].

In order to select an appropriate compression ratio, many factors should be taken into account, primarily the type of fuel (its cetane number, or CCAI index - for residual fuels), head and cylinder material, combustion chamber design, or emission of harmful and toxic components of exhaust gas [17].

\subsection{Temperature of exhaust gases}

Assuming that the temperature of the charge at the beginning of the compression stroke is constant, the temperature of the working medium at the end of this stroke is determined by the known thermodynamic relation:

$$
\mathrm{T}_{2}=\mathrm{T}_{1} \cdot \varepsilon^{\kappa-1}=\mathrm{T}_{1} \cdot\left(\frac{\mathrm{V}_{1}}{\mathrm{~V}_{2}}\right)^{\kappa-1}
$$

where: $T_{1}-$ temperature at the beginning of the compression stroke, $\mathrm{T}_{2}$ - temperature at the end of the compression stroke, $\varepsilon$ - compression ratio, $\kappa$ - isentropy exponent, $\mathrm{V}_{1}-$ volume of working medium at the beginning of the compression stroke, $\mathrm{V}_{2}$ - volume of working medium at the end of the compression stroke.

However, in determining the end of compression temperature for a known compression ratio (determined from the pressures) $\varepsilon^{\prime}$, the relation should be used:

$$
\mathrm{T}_{2}=\mathrm{T}_{1} \cdot \varepsilon^{\prime(\kappa-1)}=\mathrm{T}_{1} \cdot\left(\frac{\mathrm{p}_{2}}{\mathrm{p}_{1}}\right)^{\frac{\kappa-1}{\kappa}}
$$

where: $\mathrm{p}_{1}$ - pressure at the beginning of the compression stroke, $\mathrm{p}_{2}$ - pressure at the end of the compression stroke, $\varepsilon^{\prime}$ - compression ratio (determined from the pressures - formula 2), $\kappa$ - isentropy exponent.

So increasing the compression ratio results in an increase in $T_{2}$. The greater the difference between the mixture ignition temperature and the temperature of the exhaust gas leaving the cylinder, the more heat is converted into work. So the more the medium will be compressed during the compression stroke (increased $\varepsilon$ ), the more the medium must be decompressed to return to the parameters of the beginning, and thus the gas will do more work and the exhaust gas temperature will be lower. This is observable e.g. in the comparison of car engines: petrol $\left(\varepsilon=9-11, \mathrm{t}_{\mathrm{exh}}\right.$ $\left.=550-700^{\circ} \mathrm{C}\right)$ and Diesel $\left(\varepsilon \approx 20, \mathrm{t}_{\mathrm{exh}} \approx 400^{\circ} \mathrm{C}\right)$.

Figure 1 shows the dependence of exhaust gas temperature on the value of compression ratio of a compression ignition engine [2]. The authors of the publication analyzed the influence of the injection timing and compression ratio on the exhaust gas temperature. For all analyzed injection timing angles, a decrease in exhaust gas temperature with increasing $\varepsilon$ is evident.

In the case of an established diesel engine, a decrease in compression ratio resulting from increased combustion chamber volume should be alarming. It may be an indication of e.g. wear of bearings of the crank system or bearings of piston rods, which cause shortening of the piston distance during the compression stroke as a result of the ac- 
cumulation of increased releases in the bearings [15]. Another reason for the decrease in $\varepsilon$ can also be damage to the connecting rod in the form of bending or buckling of the connecting rod shaft [6]. The presence of too much soot in the in-cylinder space, resulting from incomplete combustion of fuel, causes a decrease in the volume of the combustion chamber and therefore an increase in the compression ratio. Thus, the decrease or increase in exhaust gas temperature and the deviation of diagnostic measures determined from it can be a source of information about the occurrence of a state of partial serviceability or unserviceability.

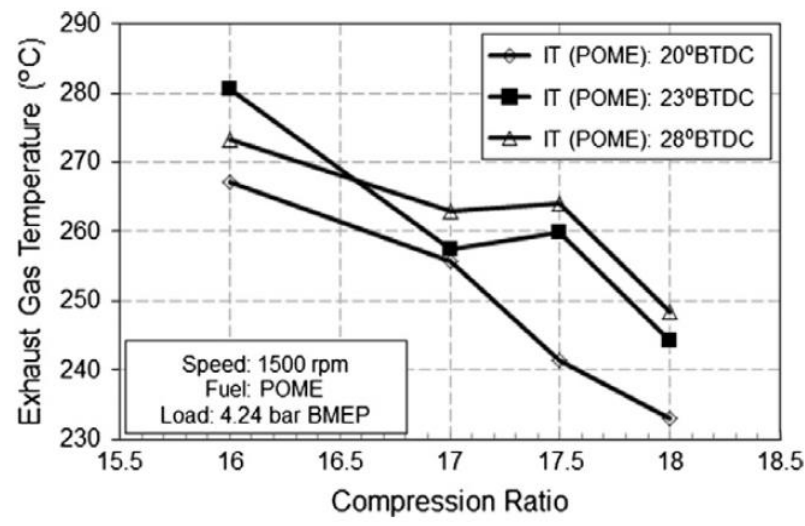

Fig. 1. Effect of injection timing and compression ratio on exhaust gas temperature; BTDC - before top dead center, POME - palm oil ethyl ester, BMEP - brake mean effective pressure [2]

\section{Research on experimental diesel engine in the conditions of actually introduced changes of the compression ratio}

Identification of the effect of decreased or increased compression ratio on engine operation is possible through experimental studies. Simulating the occurrence of the state of partial serviceability by actually introduced changes of $\varepsilon$ allows to record the selected control parameters in these conditions. The temperature of the exhaust gas allows us to determine diagnostic measures and to determine the effect of the changed compression ratio on the specific enthalpy of the exhaust gas. However, appropriate mathematical and statistical processing tools must be kept in mind in order to maximize the diagnostic informativeness of the exhaust gas temperature.

\subsection{Description of the laboratory test stand and the measurement devices used}

Experiments were carried out on the laboratory test stand of the single-cylinder, four-stroke Farymann Diesel engine type D10 (Fig. 2), located in the Laboratory of Marine Power Plants, Faculty of Mechanical Engineering and Ship Technology, Gdansk University of Technology. The basic technical data of the engine are as follows:

- nominal power $5.9 \mathrm{~kW}$,

- nominal rotational speed $1500 \mathrm{~min}^{-1}$,

- nominal torque $38 \mathrm{Nm}$,

- cylinder diameter $90 \mathrm{~mm}$,

- piston stroke $120 \mathrm{~mm}$,

- compression ratio 22:1,

- volume of cylinder stroke $765 \mathrm{~cm}^{3}$.

During the tests, the following engine control parameters were recorded:

- exhaust gas temperature and pressure,

- piston top dead centre signal,

- load current of the generator (motor)

- voltage at the generator armature clamps,

- exhaust valve opening signal.

Table 1 shows a summary of the measured control parameters and the measuring equipment used during the tests.

A multifunctional measurement and recording module type DT-9805 from Data Translation was used to record the quickly changing temperature and pressure of the exhaust gas as well as the piston top dead center signal, while Matlab software was used to record the recorded values in programmer's language. A constant crankshaft speed of 1442-1444 rpm was maintained throughout the test. The sampling frequency was approximately $7000 \mathrm{~Hz}$. The presented test results are the average of 90 consecutive measurements recorded under the same engine operating conditions determined by the engine load, crankshaft speed and ambient parameters. During the tests the engine was burning MGO type marine fuel. In order to obtain a lower compression ratio value, an additional structural element was designed and manufactured, increasing the combustion chamber volume (Fig. 2).

Tab. 1. The parameters of the Farymann D10 single cylinder diesel engine recorded on the laboratory test stand

\begin{tabular}{|c|c|c|c|c|}
\hline Item & Parameter & Measuring device & Unit & Measurement range \\
\hline 1. & Exhaust gas temperature $-\mathrm{T}_{\mathrm{sp}}$ & $\begin{array}{l}\text { Grounded type } \mathrm{K} \text { thermocouple with the } \\
\text { junction of external diameter of } 0.5 \mathrm{~mm} \text {, } \\
\text { made from inconell }\end{array}$ & ${ }^{\circ} \mathrm{C}$ & $0-1000$ \\
\hline 2. & Exhaust gas pressure in the exhaust channel $-\mathrm{p}_{\mathrm{sp}}$ & Optical pressure sensor - Optrand C12296 & V & $\begin{array}{c}0-689475.73 \mathrm{~Pa} \\
(0-100 \mathrm{psi}), \\
\text { sensitivity } 6.01 \cdot 10^{-8} \mathrm{~V} / \mathrm{Pa} \\
(41.43 \mathrm{mV} / \mathrm{psi})\end{array}$ \\
\hline 3. & $\begin{array}{c}\left.\text { Engine speed (angular position }{ }^{\circ} \mathrm{CA}\right)-\mathrm{n} \\
\text { Top dead center - TDC }\end{array}$ & $\begin{array}{l}\text { Induction engine speed sensor and TDC } \\
\text { sensor }\end{array}$ & $\min ^{-1}$ & $0-3000$ \\
\hline 4. & Load Current of the generator (armature) $-\mathrm{I}_{\mathrm{tw}}$ & Electric current meter & A & $0-15$ \\
\hline 5. & Voltage at the armature terminals $-\mathrm{U}_{\mathrm{tw}}$ & Voltmeter & $\mathrm{V}$ & $0-250$ \\
\hline 6. & Exhaust valve opening signal & $\begin{array}{l}\text { Gap type opto-isolator with a comparator } \\
\text { LM393 }\end{array}$ & $\begin{array}{c}\mathrm{V} \\
\mathrm{mm}\end{array}$ & $\begin{array}{c}0-5 \\
10 \text { (gap) }\end{array}$ \\
\hline
\end{tabular}


a)

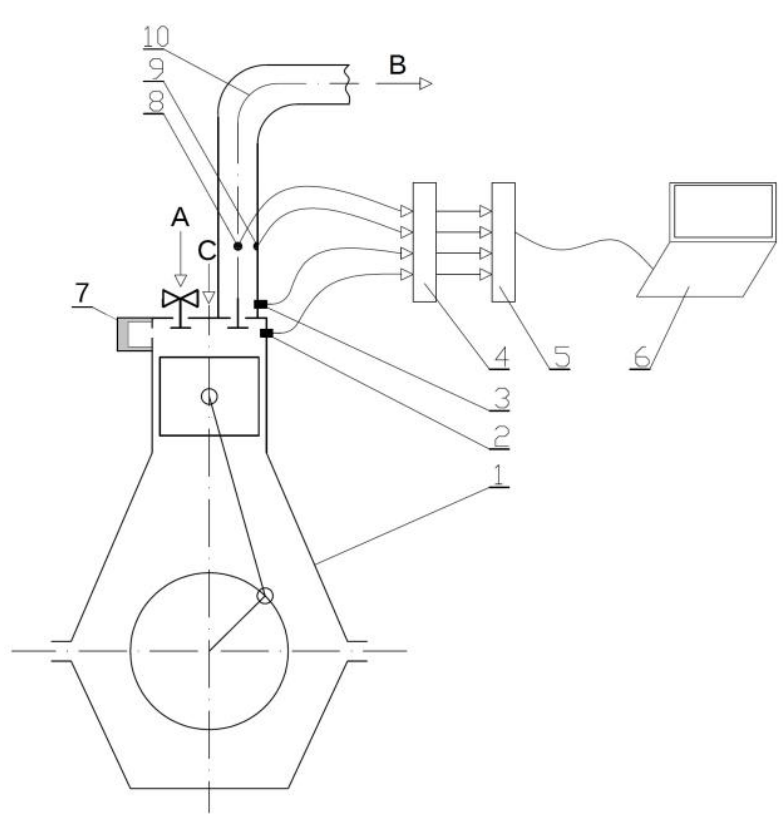

b)

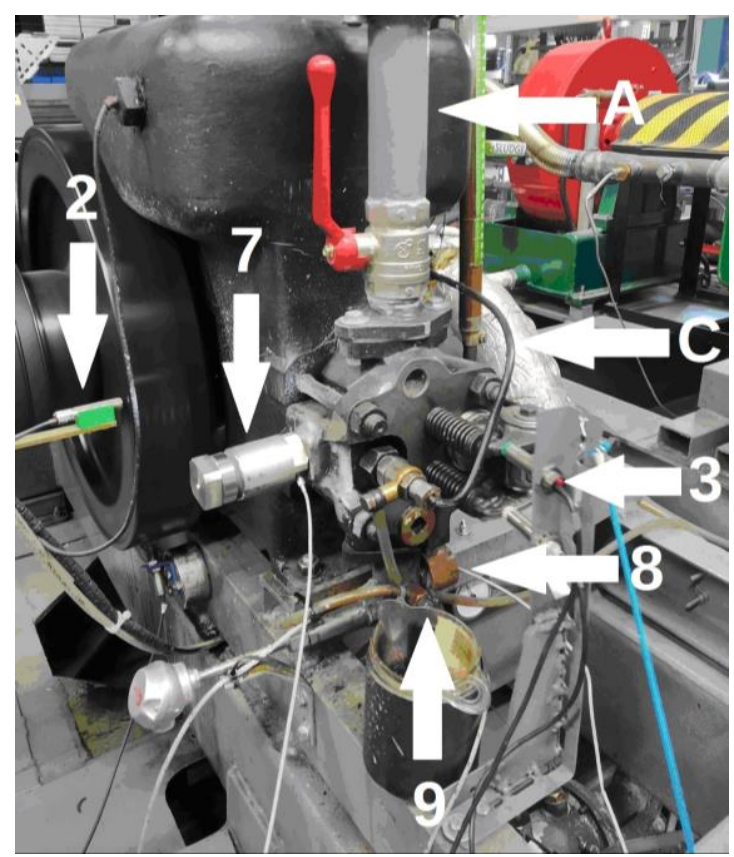

Fig. 2. a) diagram of the laboratory test stand with the fitting spots of the sensors marked: 1 - Farymann D10 engine, 2 - engine speed and TDC sensor, 3 - exhaust valve opening sensor, 4 - A/C converter, 5 - recorder, 6 - analysis software, 7 - component to increase the volume of the combustion chamber, 8 - pressure sensor, 9 - water cooled thermocouple, 10 - exhaust gas channel, A - intake air, B - exhaust gas, C - fuel line; b) view of the laboratory test stand with the fitting spots of the sensors of the recorded parameters marked: 2 - engine speed and TDC sensor, 3 - exhaust valve opening sensor, 7 component to increase the volume of the combustion chamber with a pressure sensor for the medium inside the combustion chamber, 8 - pressure sensor, 9 - water cooled thermocouple, A - intake air, C - fuel line

\subsection{Experimental research program}

In the research realised by the author of this paper, the main aim was to determine the diagnostic informativeness of the parameter, i.e. quickly changing temperature of the exhaust gas of a diesel engine, depending on the actually introduced changes in selected parameters of its constructional structure. Therefore, it was decided to use a static, randomized and complete experiment plan [4]. This paper presents part of the results of a larger program of research and statistical analysis undertaken, namely the evaluation of the significance of the effect of the compression ratio on the specific enthalpy of the exhaust gas of a single-cylinder diesel research engine. On this basis it is possible to transfer the results of laboratory tests to full-size marine engines, for their diagnosis (diagnostic conclusions).

The experimental research was carried out on the Farymann Diesel engine type D10. The research object of thermo-flow processes was defined by constructional elements limiting the cylinder working space, as well as by the channels of inlet air and outlet exhaust gases. In the research and analyses carried out, the processes occurring in the intracylinder space were not subjected to, and only the signal of quick-changing temperature of exhaust gases recorded in the exhaust gas channel was examined. The input parameters, output parameters, disturbing factors and constants are summarized in Fig. 3. In case of the applied model, the tested engine was treated as an object of diagnosis on the assumption that the set of $\mathrm{U}$ forcing is the parameters of engine operation (load, torque, rotational speed), which do not change. However, the state parameters X (of the con- structional structure) are variable - in the discussed case, it is the degree of compression of the engine. The output parameter $\mathrm{Y}_{1}$, which is the exhaust gas pressure, is important for determining the exhaust gas enthalpy flow of the engine $\dot{\mathrm{H}}_{\text {spal }}$. Diagnostic measures $\mathrm{Y}_{2}$ were determined on the basis of the recorded signal of quickly changing temperature of exhaust gases, however, in the present paper we discuss only the specific enthalpy of the exhaust gas stream averaged over one cycle of diesel engine operation $-\mathrm{h}_{\mathrm{sr}}$.

The evaluation of the effect of variable engine load as an input parameter on selected diagnostic measures was described by the author in the article [7]. The variable value of the inlet air flow area, as a simulation of the loss of purity of the inlet air duct, was analyzed in the paper [8]. Meanwhile, the evaluation of the influence of the structure parameter, which is the reduced injector opening pressure (spring relaxation), as well as the analysis of the influence of the mentioned input parameters (load, inlet air flow area, injector opening pressure, and compression ratio) on all analyzed diagnostic measures (described in [7]) are in preparation for publication.

In steady-state operation of a diesel engine, three characteristics of its operation are possible [1]. In the carried out research, the speed, regulator characteristic was used, with the rotational speed changing in the range of astatic operation of the regulator. In this case, the engine is loaded by increasing the generated effective torque (increasing the fuel dose per engine cycle), at a constant value of crankshaft rotational speed. 


\section{DISTURBING QUANTITIES:}

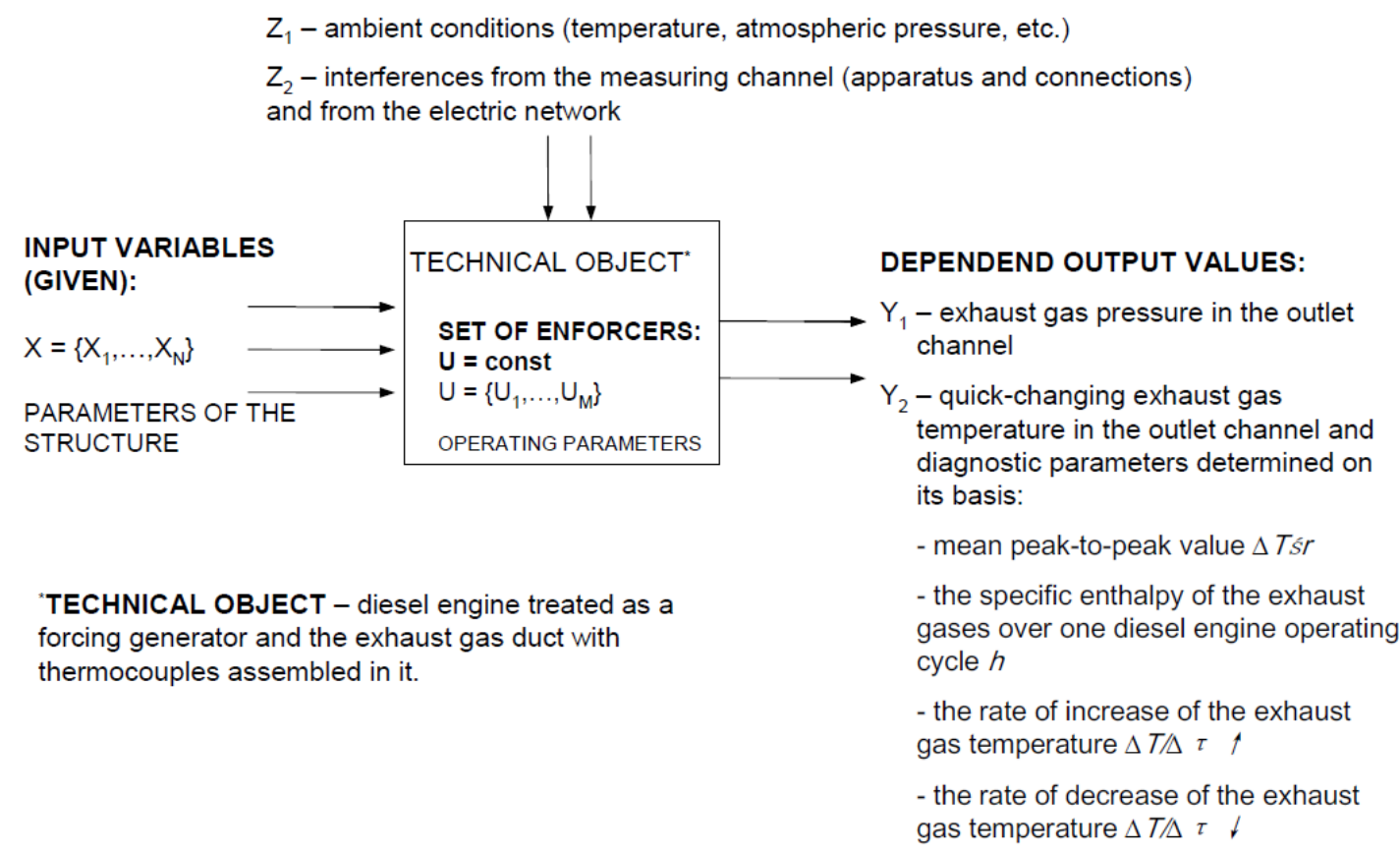

Fig. 3. Simplified physical model of a diagnostic subject for an elimination experimental test realized according to a randomized complete plan

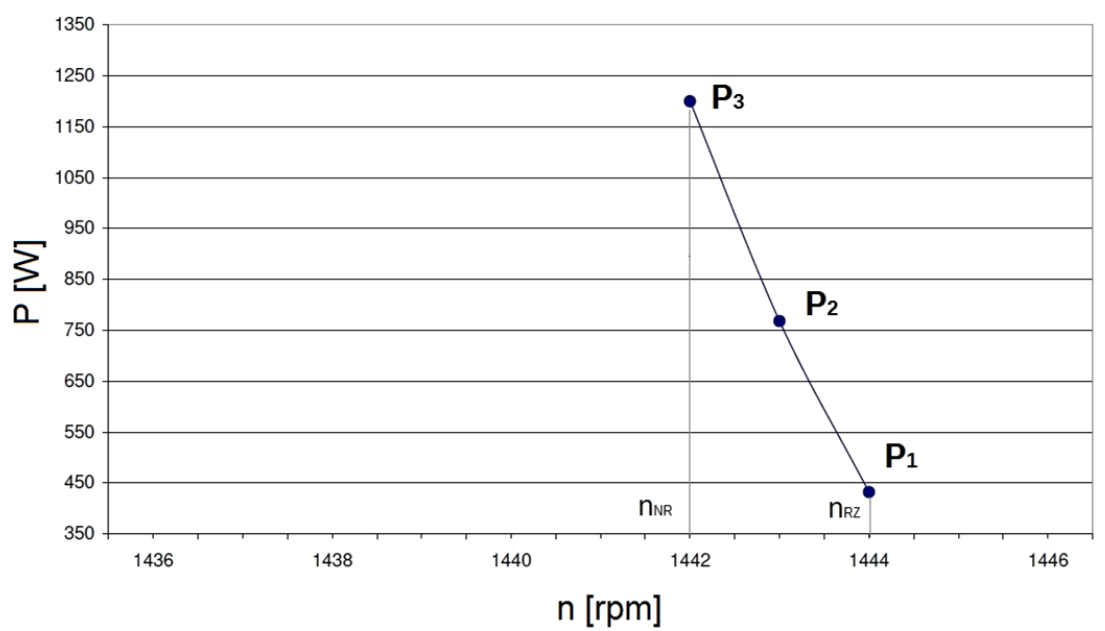

Fig. 4. The characteristic - regulator load variation of Farymann Diesel engine type D10 as a function of crankshaft rotational speed used during testing (variable fuel dose per engine cycle at crankshaft rotational speed stabilized by the regulator), $\mathrm{n}_{\mathrm{NR}}-$ rotational speed regulator setting, $\mathrm{n}_{\mathrm{RZ}}-$ real rotational speed

During the experimental research carried out on Farymann Diesel engine type D10 the measurements were realized for 3 points of work according to the regulator characteristics (Fig. 4). In the discussed stage of research and mathematical processing and statistical analysis, changes were made in the structure parameter, i.e. combustion chamber volume, which was represented in the values of engine compression ratio. The reference value for the engine being tested was $\varepsilon_{\text {REF }}=\varepsilon_{1}=22: 1$, while the reduced value was $\varepsilon_{2}=21: 1$, due to design limitations. Reduction of compression ratio was realized by application of additional structural element, increasing the volume of combustion chamber by about $0.125-10^{-5} \mathrm{~m}^{3}\left(\Delta \mathrm{V}_{\mathrm{k}}\right)$, with initial (reference) volume of combustion chamber $V_{\mathrm{k} 1}=3.787 \cdot 10^{-5} \mathrm{~m}^{3}$ and volume of cylinder stroke $\mathrm{V}_{\mathrm{s}}=79.5 \cdot 10^{-5} \mathrm{~m}^{3}$.
During the diagnostic testing of an engine, at the time of established operation, diagnostic parameters are determined from among its output parameters, which react more strongly to changes in the values of structural parameters than to changes in the values of input parameters, forcing the realized working process. The basic condition for selecting adequate diagnostic parameters is that the sensitivity of the output parameter to the structure parameter is much higher than its sensitivity to the input parameter [3]. Comparing the sensitivities of multiple control parameters, given in different units of measurement, requires taking relative values of input, output and structure parameters for this purpose. There are many methods to assess the significance of the influence of the forcing parameters of the analyzed physical process on its course, but in this study a static 
randomized complete program was used [4], and the assumed null hypothesis is that there is no influence of the input factor on the output factor. The influence of an input factor is considered significant when the calculated value of the used statistic is equal to or greater than the critical value, given in the tables for the assumed value of the significance level $\alpha$ and the number of degrees of freedom $\mathrm{f}=\mathrm{n}-1$. It was considered best to use the F statistic of the FisherSnedecor distribution $[4,9,16]$, as the conditions for using one-sided parametric tests were met. In the conducted research, it was assumed that the measurement results of all control parameters can be modeled as random variables with a normal distribution, a defined expected value and variance, which is a measure of the spread of measurement results around the expected value. The variances of the random variables were also assumed to be equal or close in value, and the parametric tests for variance used are with a one-sided critical area. The possibility of making an error of the first type associated with the assumed significance level $\alpha$, i.e., the probability of rejecting the null hypothesis when it is true, and the possibility of making an error of the second type, i.e., accepting the null hypothesis when it is false, of $\beta=1-\alpha$ were considered.

Table 2 presents the matrix of the experimental research program, in this case the randomized static plan, allowing the evaluation of the significance of the influence of the input factor considered in the diagnostic tests of the engine - the compression ratio of the engine realized within the specified range of variability, on the diagnostic parameter determined in these tests (the output factor), which is the specific enthalpy of the exhaust gas stream within the range of one working cycle $-\mathrm{h}_{\text {spal }}$.

Table 2. Experimental research program matrix - static randomized complete plan

\begin{tabular}{|l|c|c|c|}
\hline \multirow{2}{*}{$\begin{array}{l}\text { Level of } \\
\text { input factor }\end{array}$} & \multicolumn{3}{|c|}{ Number of experience } \\
\cline { 2 - 4 } & 1 & $\ldots$ & 4 \\
\hline$\varepsilon_{1}$ & $\mathrm{~h}_{\text {spal11 }}$ & $\ldots$ & $\mathrm{h}_{\text {spal41 }}$ \\
\hline$\varepsilon_{2}$ & $\mathrm{~h}_{\text {spal } 12}$ & $\ldots$ & $\mathrm{h}_{\text {spal42 }}$ \\
\hline
\end{tabular}

The test (calculation) value of the F statistic of the Fisher-Snedecor distribution is determined from the following relationship [4]:

$$
\mathrm{F}=\frac{\sum_{\mathrm{i}=1}^{\mathrm{p}} \mathrm{n}_{\mathrm{i}}\left(\overline{\mathrm{h}_{\mathrm{i}}}-\overline{\mathrm{h}}\right)^{2}(\mathrm{n}-\mathrm{p})}{\left[\sum_{\mathrm{i}=1}^{\mathrm{p}} \Sigma_{\mathrm{j}=1}^{\mathrm{q}}\left(\overline{\overline{\mathrm{h}_{i}}}-\overline{\mathrm{h}}\right)^{2}-\sum_{\mathrm{i}=1}^{\mathrm{p}} \mathrm{n}_{\mathrm{i}}\left(\overline{\mathrm{h}_{\mathrm{i}}}-\overline{\mathrm{h}}\right)^{2}\right](\mathrm{p}-1)}
$$

where: $n_{i}$ - number of measurements of specific enthalpy at a given level, $n-$ total number of measurements, $\overline{h_{i}}-$ average specific enthalpy from the measurements in the $i$ line, $\bar{h}$ - average specific enthalpy from all measurements, $h_{i j}-$ the value of the $\mathrm{j}$ specific enthalpy at the $\mathrm{i}$ level, $\mathrm{p}$ - number of levels of variation of the input medium (compression ratio).

The calculated value of $F_{o b l}$ statistic is compared with its critical value $F_{k r}$ determined from the statistical table, for the assumed significance level $\alpha$ and for the determined numbers of degrees of freedom defined for the numerator and denominator: $f_{1}$ and $f_{2}$. If the determined value of $F_{o b l}$ is greater than or equal to the critical value of $\mathrm{F}_{\mathrm{kr}}$, then the influence of the factor under study is to be considered sig- nificant. Otherwise, the input factor under study is considered to have no significant effect on the output factor within the range of variation under study and at the assumed significance level. Additionally, once a factor is considered significant $\left(\mathrm{F}_{\mathrm{obl}}>\mathrm{F}_{\mathrm{kr}}\right)$, it is possible to compare the difference $\Delta \mathrm{F}=\mathrm{F}_{\mathrm{obl}}-\mathrm{F}_{\mathrm{kr}}$ for individual diagnostic measures. This allows us to assess which diagnostic measure is more strongly influenced by the input parameter (e.g. structure) the higher the $\Delta \mathrm{F}$, the greater the influence [10].

In order to get the value of the $\mathrm{F}_{\mathrm{obl}}$ statistic and the difference $\Delta \mathrm{F}$, and thus to answer the question regarding the significance of the influence of selected input factors (structure) of the engine on the diagnostic measure, i.e. average specific enthalpy of exhaust gases within one cycle, we had to proceed in accordance with the scheme of research realization - Fig. 5 .

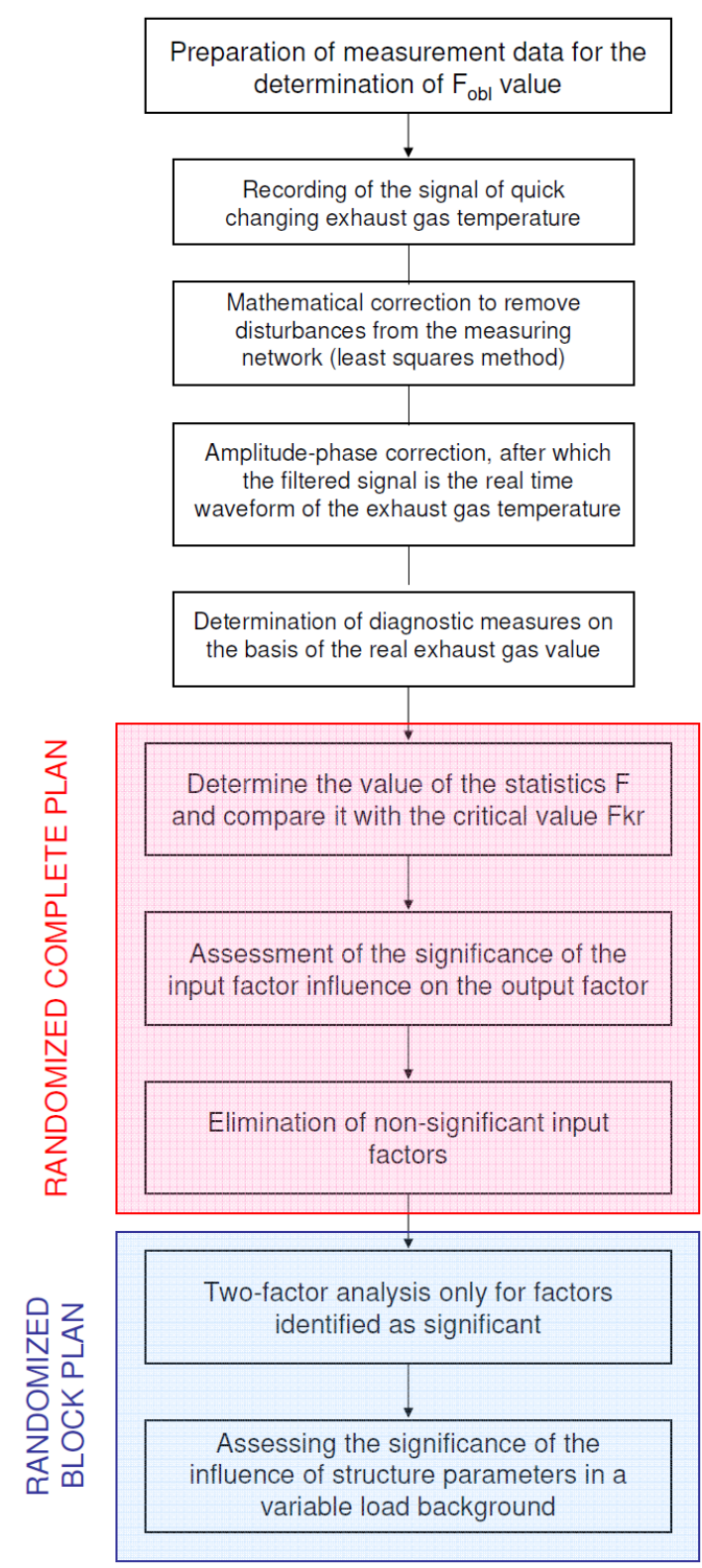

Fig. 5. Steps in determining the F-statistic of the Fisher-Snedecor distribution for diagnostic purposes 


\subsection{Statistical and qualitative analysis of the results achieved}

The values of the output factor, i.e. the specific enthalpy of the exhaust gas stream during one cycle of engine operation, for three states of the engine steady-state load, are presented in Tables $3 \mathrm{a}-\mathrm{c}$. The points $\mathrm{P}_{1}, \mathrm{P}_{2}$ and $\mathrm{P}_{3}$ determined by these parameters result from the applied control characteristics of the engine operation (Fig. 4).

The following zero hypothesis was used to determine the value of the $\mathrm{F}_{\mathrm{obl}}$ statistic:

\section{$\mathrm{H}_{0}$ : the value of compression ratio has no effect on the value of specific enthalpy of the exhaust gas stream averaged over one engine operating cycle $\left(S_{I I}{ }^{2}=S_{I}{ }^{2}\right)$}

On the basis of the numerical data summarized in Tables $3 \mathrm{a}-\mathrm{c}$ and the applied level of significance $\alpha=0.05$ and the assumption of the right-side critical area, the specific enthalpy of the exhaust gas stream within one engine cycle was determined for each measurement point $\left(\mathrm{P}_{\mathrm{i}}\right)$, the number of degrees of freedom for the numerator and denominator $\left(f_{1}=1\right.$ and $\left.f_{2}=6\right)$. Then, the critical value of the statistic $\mathrm{F}_{\mathrm{kr}}=\mathrm{F}(0.05 ; 1 ; 6)=5.9874$ was read from statistical tables [4] and the values of $F_{\text {obl }}$ were calculated, whose values are presented in Table 4 . In the case of all analysed characteristic points the condition: $\mathrm{F}_{\mathrm{obl}}>\mathrm{F}_{\mathrm{kr}}$ (positive $\Delta \mathrm{F}$ ) is fulfilled, so the zero hypothesis should be rejected and it should be assumed in further diagnostic tests that in the considered range of variation of the engine load and the value of the compression ratio it $(\varepsilon)$ has a significant influence on the specific enthalpy of the exhaust gases determined within one cycle of the diesel engine work.

Table 3a. Value (average within one working cycle) of exhaust gas enthalpy $h_{\text {sr }}$ for variable values of compression ratio in point $P_{1}$

\begin{tabular}{|c|c|c|c|c|c|c|}
\hline & \multicolumn{5}{|c|}{$\mathrm{P}_{1}(432 \mathrm{~W} ; 5.1 \mathrm{~A} ; 72 \mathrm{~V})$} \\
\hline \multirow{2}{*}{ Point } & \multirow{2}{*}[-]{} & 1 & 2 & 3 & 4 & $\mathrm{y}_{\mathrm{i}}$ \\
\hline$\varepsilon_{1}$ & 22 & 12.1299 & 12.1986 & 12.2763 & 12.2176 & 12.2056 \\
\hline$\varepsilon_{2}$ & 21 & 13.3422 & 13.0606 & 12.9157 & 12.8373 & 13.0389 \\
\hline
\end{tabular}

Table 3b. Value (average within one working cycle) of exhaust gas enthalpy $\mathrm{h}_{\text {sr }}$ for variable values of compression ratio in point $\mathrm{P}_{2}$

\begin{tabular}{|c|c|c|c|c|c|c|}
\hline & \multicolumn{5}{|c|}{$\mathrm{P}_{2}(768 \mathrm{~W} ; 6.8 \mathrm{~A} ; 96 \mathrm{~V})$} \\
\cline { 3 - 8 } & \multirow{2}{*}{ Point } & $1-]$ & 2 & 3 & 4 & $\mathrm{y}_{\mathrm{i}}$ \\
\hline$\varepsilon_{1}$ & 22 & 13.8992 & 13.6571 & 13.4404 & 13.3947 & 13.5979 \\
\hline$\varepsilon_{2}$ & 21 & 14.4089 & 14.5475 & 14.0739 & 14.2577 & 14.3220 \\
\hline
\end{tabular}

Table 3c. Value (average within one working cycle) of exhaust gas enthalpy $\mathrm{h}_{\text {sr }}$ for variable values of compression ratio in point $\mathrm{P}_{3}$

\begin{tabular}{|c|c|c|c|c|c|c|}
\hline & \multicolumn{5}{|c|}{$\mathrm{P}_{3}(1200 \mathrm{~W} ; 8.5 \mathrm{~A} ; 120 \mathrm{~V})$} \\
\hline \multirow{2}{*}{ Point } & \multirow{2}{*}[-]{} & 1 & 2 & 3 & 4 & $\mathrm{y}_{\mathrm{i}}$ \\
\hline$\varepsilon_{1}$ & 22 & 15.4712 & 15.4883 & 15.3075 & 15.3299 & 15.3992 \\
\hline$\varepsilon_{2}$ & 21 & 16.4605 & 15.8383 & 15.7786 & 15.8411 & 15.9796 \\
\hline
\end{tabular}

Table 4. Value of statistic $\mathrm{F}_{\mathrm{obl}}$ and $\left(\Delta \mathrm{F}=\mathrm{F}_{\mathrm{obl}}-\mathrm{F}_{\mathrm{kr}}\right)$ for a reduced compression ratio and its effect on $\mathrm{h}_{\text {sr }}$

\begin{tabular}{|c|c|}
\hline Points according to the regulator characteristics & $\mathrm{F}_{\text {obl i }}\left(\Delta \mathrm{F}=\mathrm{F}_{\text {obl }}-\mathrm{F}_{\mathrm{kr}}\right)$ for $\mathrm{h}_{\text {sr }}[\mathrm{kJ} / \mathrm{kg}]$ \\
\hline $\mathrm{P}_{1}(432 \mathrm{~W} ; 5.1 \mathrm{~A} ; 72 \mathrm{~V})$ & $\begin{array}{c}52.34 \\
(46.35)\end{array}$ \\
\hline $\mathrm{P}_{2}(768 \mathrm{~W} ; 6.8 \mathrm{~A} ; 96 \mathrm{~V})$ & 22.12 \\
& $(16.13)$ \\
\hline $\mathrm{P}_{3}(1200 \mathrm{~W} ; 8.5 \mathrm{~A} ; 120 \mathrm{~V})$ & 11.99 \\
& $(6.00)$ \\
\hline
\end{tabular}

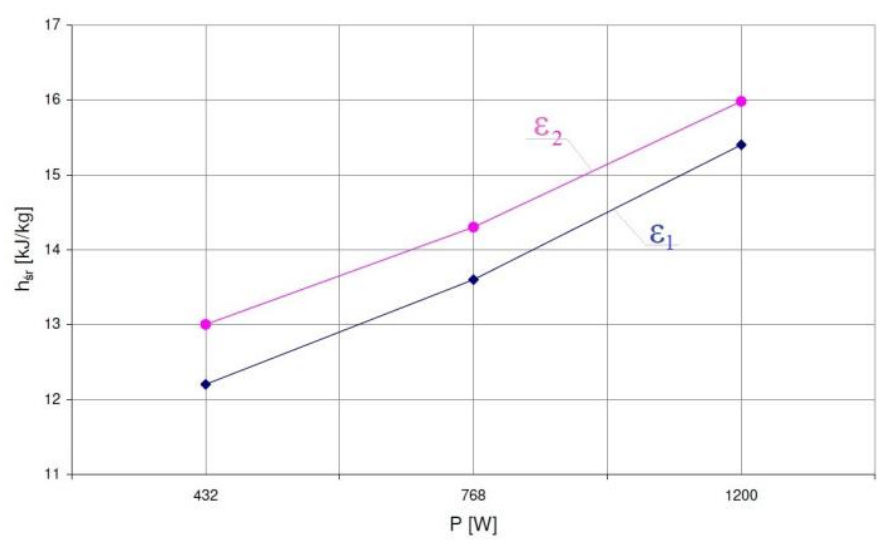

Fig. 6. Effect of the compression ratio $(\varepsilon)$ on the value of the average within one cycle of the exhaust gas enthalpy $\mathrm{h}_{\text {sr }}$ for diesel engine loads according to the regulator characteristics 
It can also be seen (Table 4) that at point $\mathrm{P}_{2}$ the value of $\Delta \mathrm{F}$ is almost 3 times higher and at point $P_{1}$ almost 8 times higher than at $\mathrm{P}_{3}$. It is therefore possible to conclude that for lower loads of the diesel engine, the effect of compression ratio on $h_{\text {sr }}$ is greater than for higher loads.

In developing a methodology for diagnosing a diesel engine based on quickly changing exhaust gas temperature, it is important to consider a number of factors. First, from the output parameters obtained during engine testing, it is necessary to select those that contribute the greatest amount of diagnostic information about the engine condition. Next, an appropriate tool should be found to assess the significance of the effect for parameters presented in different units of measurement. After the selection of an appropriate test program and a method of statistical analysis, a scheme for carrying out the tests should be developed. It should take into account, among others, mathematical processing (correction) of the obtained measurement signal by means of individually selected filters. At the final stage - during the assessment of the significance of the considered input factors on the output, both single and multivariate analysis is possible. In the case of the discussed analysis of variance, the determination of the value $\Delta \mathrm{F}=\mathrm{F}_{\mathrm{obl}}-\mathrm{F}_{\mathrm{kr}}$ also allows us to assess how large is the influence of the input factor on the output. On the basis of carried out experimental research and statistical analysis of the obtained results, it is possible to assess the influence of the compression ratio on the value of one cycle average enthalpy of exhaust gas $h_{\text {sr }}$ determined on the basis of quickly changing temperature of exhaust gas (Fig. 6). Thanks to obtaining the results of similar analysis also for other diagnostic measures calculated on the basis of this parameter and for other structure parameters, it is possible to develop the diagnosis method- ology based on this temperature. This is particularly important in the diagnostics of engines with limited controllability, in which the measurement of the exhaust gas temperature is the main source of information on the technical condition of the working spaces of the diesel engine. The conducted research shows that a decrease in the compression ratio (resulting from the occurrence of partial serviceability or unserviceability) influences significantly the increase in the average value within one cycle of the exhaust gas enthalpy. Additionally, performing a statistical analysis based on the value of $\Delta \mathrm{F}$ allows to determine the significance of the effect of $\varepsilon$ on $h_{\text {srr }}$.

\section{Comments and final conclusions}

The compression ratio $\varepsilon$ is an important quantity characterizing the operation of a diesel engine. It can be determined either as a design parameter or by analysis of the indicator diagram. In both cases the engine user should be alerted by its increase or decrease, showing the occurrence of a state of partial serviceability or unserviceability. The measurement of quick changing temperature of exhaust gases allows to determine the influence of the change of input value $\varepsilon$ on diagnostic measure, that is $\mathrm{h}_{\mathrm{sr}}$. It is possible due to application of statistical tool that is F statistic of Fisher-Snedecor distribution. In the investigated range of engine load variation the significant influence of $\varepsilon$ on $h_{\text {sr }}$ was determined. The applied research and analytical method was found to be effective for evaluating the influence of significance of changes of the input factor - structure $(\varepsilon)$ on the output parameter $\left(\mathrm{h}_{\mathrm{sr}}\right)$. It is also possible to determine other diagnostic measures from the quickly changing exhaust gas temperature and determine the effect of $\varepsilon$ on them by using F statistics.

\section{Nomenclature}

BMEP brake mean effective pressure

BTDC before top dead center

$\mathrm{F}$ test value of the statistic of the Fisher-Snedecor

$\varepsilon \quad$ compression ratio

POME palm oil ethyl ester

$\kappa \quad$ isentropy exponent

$\eta_{\mathrm{m}} \quad$ mechanical efficiency

$\eta_{\mathrm{ts}} \quad$ theoretical efficiency of the Seiliger-Sabathe cycle

\section{Bibliography}

[1] BALCERSKI, A. Siłownie okrętowe: podstawy termodynamiki, silniki i napędy główne, urządzenia pomocnicze, instalacje. Wydawnictwo Politechniki Gdańskiej. Gdańsk 1990.

[2] DEBNATH, B.K., SAHOO, N., SAHA, U.K. Thermodynamic analysis of variable compression ratio diesel engine running with palm oil methyl ester. Energy Conversion and Management. 2013, 65, 147-154.

https://doi.org/10.1016/j.enconman.2012.07.016

[3] KORCZEWSKI, Z. Diagnostyka eksploatacyjna okrętowych silników spalinowych - tłokowych i turbinowych. Wybrane zagadnienia. Wydawnictwo Politechniki Gdańskiej. Gdańsk 2017.

[4] KORZYŃSKI, M. Metodyka eksperymentu. Planowanie, realizacja i statystyczne opracowanie wyników eksperymentów technologicznych. Wydawnictwo Naukowo-Techniczne. Warszawa 2017.

[5] ŁUTOWICZ, M. Badania wstępne możliwości oceny stanu technicznego układów cylindrowych silnika na podstawie analizy procesu sprężania. Zeszyty Naukowe Akademii Marynarki Wojennej. 2004, 2(157), 97-107.

[6] MIJAS, Ł., REITER, E., KUKIEŁKA, K. Wykorzystanie systemu ANSYS Workbench do analizy statycznej korbowodów. Autobusy: technika, eksploatacja, systemy transportowe. 2013, 14(10), 315-317.

[7] PUZDROWSKA, P. Statystyka F rozkładu Fishera-Snedecora jako narzędzie do oceny istotności wpływu mocy silnika o ZS na wybrane miary diagnostyczne. Journal of Polish CIMAC. 2019, 14(1/18), 177-186.

http://www.polishcimeeac.pl/

[8] PUZDROWSKA, P. Evaluation of the significance of the effect of the active cross-sectional area of the inlet air channel on the specific enthalpy of the exhaust gas of a diesel engine using statistics $\mathrm{F}$ of the Fisher-Snedecor distribution. Combustion Engines. 2020, 182(3), 10-15.

https://doi.org/10.19206/CE-2020-302 
[9] SHANNON, C.E. A mathematical theory of cryptography. A classified memorandum for Bell Telephone Labs. USA 1945.

[10] SMIRNOW, N.W., DUNIN-BARKOWSKI, I.W. Kurs rachunku prawdopodobieństwa i statystyki matematycznej dla zastosowań technicznych. Państwowe Wydawnictwo Naukowe. Warszawa 1969.

[11] WAJAND, J.A., WAJAND, J.T. Tłokowe silniki spalinowe średnio- i szybkoobrotowe. Wydawnictwo Naukowo-Techniczne. Warszawa 2000.

[12] WARDZIŃSKI, F. Samochodowe silniki spalinowe, WSiP, Warszawa 1968.

[13] WIŚNIEWSKI, S. Termodynamika techniczna. Wydawnictwo Naukowo-Techniczne. Warszawa 2005.

[14] WITKOWSKI, K. The increase of operational safety of ships by improving diagnostic methods for marine diesel

Patrycja Puzdrowska, MEng. - Faculty of Mechanical Engineering and Ship Technology, Gdansk University of Technology.

e-mail:patpuzdr@pg.edu.pl engine. TransNav the International Journal on Marine Navigation and Safety of Sea Transportation. 2017, 11(2), 317321. https://doi.org/10.12716/1001.11.02.15

[15] WŁODARSKI, J.K. Okrętowe silniki spalinowe. Obciążenia eksploatacyjne. Wydawnictwo Wyższej Szkoty Morskiej w Gdyni. Gdynia 1995.

[16] WOJTATOWICZ, T.W. Metody analizy danych doświadczalnych. Wybrane zagadnienia. Wydawnictwo Politechniki Łódzkiej. Łódź 1998.

[17] WOŚ, P., JAWORSKI, A., KUSZEWSKI, H. et al. Technical and operating problems yielded from setting up the optimum value of geometric compression ratio in piston engines. Combustion Engines. 2016, 164(1), 3-14. https://doi.org/10.19206/CE-116483 